\title{
Extensive reading practices in the Arabian Gulf region
}

\author{
Joel C. Meniado a $b *$ (D) \\ a SEAMEO Regional Language Centre, 30 Orange Grove Road, Singapore 258352, Singapore \\ ${ }^{b}$ University of Toronto, 158 St. George Street, Toronto, Ontario ON M5S 2V8, Canada
}

\begin{tabular}{l|l|l} 
Received 9 September 2020 & Received in revised form 31 January 2021 & Accepted 9 February 2021
\end{tabular}

APA Citation: Meniado, J.C. (2021). Extensive reading practices in the Arabian Gulf region. Eurasian Journal of Applied Linguistics, 7(1), 222-239.

Doi: $10.32601 /$ ejal.911262

\begin{abstract}
This study examined the English extensive reading (ER) programs across the Arabian Gulf region. It investigated the ER models and approaches adopted by different higher education institutions (HEIs) in the region, their ER practices and activities, and the challenges they encountered in implementing their ER programs. Utilizing qualitative research design with seventeen (17) cases from prominent colleges and universities in Saudi Arabia, United Arab Emirates, Qatar, Bahrain, Oman, and Kuwait, the study found that most English ER programs in the region adopted the Graded Readers approach with the Supervised-Modified ER model and course-component integration scheme. The study further discovered that the ER programs varied in terms of duration, number of hours and sessions, target number of words, required number of books read, engagement and enrichment activities, and assessment system. Lastly, the study also found that HEIs in the region experienced challenges in sustaining meaningful, varied, and sufficient resources, changing the negative attitudes of the stakeholders toward extensive reading, providing more sufficient space for ER in English language curriculum, and building a strong culture of reading in the community as a whole. The study concludes with recommendations on how to improve English ER implementation in the Arabian Gulf region.
\end{abstract}

(C) 2021 EJAL \& the Authors. Published by Eurasian Journal of Applied Linguistics (EJAL). This is an open-access article distributed under the terms and conditions of the Creative Commons Attribution license (CC BY-NC-ND) (http://creativecommons.org/licenses/by-nc-nd/4.0/).

Keywords: Extensive reading, extensive reading practices, reading program, reading in the Arab world, teaching reading

\section{Introduction}

English proficiency in the Arabian Gulf region remains one of the world's lowest (EF Education First, 2019). In the recent EF English Proficiency Index report, the average proficiency score of test takers from Saudi Arabia, United Arab Emirates, Qatar, Bahrain, Kuwait, and Oman was 46.35 which is described as very low (EF Education First, 2019). TOEFL iBT test and score data summary from 2014 to 2018

\footnotetext{
* Corresponding author. Tel.: +65 6885-7841

E-mail address: joel.meniado@mail.utoronto.ca

http://dx.doi.org/10.32601/ejal.911262
} 
also revealed that the average overall score across the six Gulf countries was 64.7/120 with reading as the lowest having an average score of 16.96/30 (Educational Testing Service [ETS], 2015, 2016, 2017, 2018, 2019). Moreover, the 2018 IELTS Test Taker Performance Report (Academic Module) also indicated that Saudi Arabia, Oman, UAE, Qatar, and Kuwait had an average overall band score of 5.25/9.00 with reading (4.94) and writing (4.87) as the lowest (IELTS Partners, 2018). These persistent results can be partly attributed to Arab learners' poor English reading comprehension performance due to lack of strong reading culture, ineffective English reading instruction in schools, and limited support from parents and teachers (Al-Mahrooqi \& Denman, 2016; Al-Qahtani, 2016; Erguvan, 2016; Meniado, 2018).

One of the popular approaches in developing reading comprehension among EFL learners in various parts of the world is the extensive reading (ER) program. It is an approach where EFL learners read large amounts of texts to develop good reading habits and strong liking for reading (Bamford \& Day, 2004). Moreover, it is an environment where readers voluntarily and silently read self-selected, simplified texts written in a foreign language without performing any subsequent linguistic tasks (Milliner, 2017; Park, 2020). Lastly, it is a reading pedagogy which is guided by the following principles: 1) The reading material is easy; 2) A variety or reading material on a wide range of topics must be available; 3) Learners choose what they want to read; 4) Learners read as much as possible; 5) The purpose of reading is usually related to pleasure, information, and general understanding; 6) Reading is its own reward; 7) Reading is usually faster rather than slower; 8) Reading is individual and silent; 9) Teachers orient and guide their students; and 10) The teacher is a role model of a reader (Bamford \& Day, 2002, pp. 137-140).

ER has been proven to be effective in improving language learners' general language proficiency, macro-linguistic skills development, and vocabulary knowledge (Chang \& Renandya, 2017), in addition to its recognized importance in improving motivation to read, positive attitude toward reading, and confidence to read (Chien \& $\mathrm{Yu}, 2015)$. This approach is consistent with the optimal input hypothesis of Krashen (2019) which claims that human beings acquire language and develop literacy from comprehensible, compelling, rich, and abundant inputs, which can be in a form of reading large amount of easy written texts such as graded readers. When L2 learners are optimally engaged in guided self-selected reading (GSSR) which happens in the context of extensive reading, they become gifted language acquirers, proficient L2 users, passionate readers, and life-long knowledge seekers (Krashen, 2019).

\section{Review of the Literature}

Many empirical studies in various contexts have investigated the effectiveness of ER. These studies found that ER is an effective approach in improving reading proficiency, reading speed, reading techniques, writing, speaking, listening, vocabulary, and grammar skills of L2 learners (Chang \& Renandya, 2017; Day et al, 2011; Nakanishi, 2015; Suk, 2017; Walker, 1997). They also discovered that ER 
cultivates a sense of ownership, autonomy, and accomplishment among readers, thereby developing positive motivation and attitude toward reading (Day et al, 2011). In the Arabian Gulf setting, empirical studies of Abdellah (2013), Al-Hammad (2009), Al-Homoud \& Alsalloum (2012), Al-Homoud \& Schmitt (2009), Al-Mansour \& AlShorman (2014), Al-Nafisah (2015), and Salameh (2017) revealed significant roles of ER in improving Saudi EFL university students' reading comprehension performance, reading fluency, vocabulary development, writing performance, motivation, and positive attitudes toward learning English language and reading. Demirci's (2019) study also found that gamified extensive reading encourages male Emirati ESL learners to read, while Al-Damen's (2018) study discovered that extensive reading through an ER quiz site was effective in developing reading motivation and learner autonomy among Omani college-level EFL students.

Extensive reading has varied types and structures. Day et al. (2011) classified ER according to approach and materials used: 1) Class Readers; 2) Graded Readers; and 3) Reading Circles. In Class Reader type, all students read the same text in class at the same time and do the same post-reading activities. The teacher selects the reading texts and controls the reading processes and activities. In Graded Reader type, on the other hand, the teacher gives students the freedom to choose the book they want based on their existing levels and interests. He guides the students in identifying their reading levels, guides them in choosing the right books, monitors their progress, and motivates them to read more. The students are in control of their own individual reading activities and are encouraged to keep reading logs or record sheets to ensure accountability. Lastly, in the Reading Circle type, the teacher places students into small groups, with each group reading the same graded reader at home and discussing the content in class. Students read independently, take notes, and participate in in-class group discussion with a specific role (e.g., discussion leader, summarizer, connector, word master, etc.)

Day (2015) also categorized ER based on structure and compliance with the ER principles: 1) Supervised ER; 2) Independent ER; and 3) Blended ER. The supervised ER or instructed ER is the type where teachers fully control and monitor the program. It can come in various forms such as: a) pure ER where all the 10 principles (Bamford \& Day, 2002) are complied; b) modified ER where many of the ER principles are observed; c) ER light where some of the ER principles are followed; and d) fringe ER where the program is ER only by name. The Independent ER, on the other hand, is the non-instructed type of ER program where learners engage in ER without teacher monitoring. Lastly, the Blended ER is the type which combines extensive reading and intensive reading activities. It teaches students reading strategies while keeping them engaged in reading lengthy texts. Publishing companies gradually integrate this type in various commercial ELT books to bridge the gap between the demands of the curriculum and the need to develop a strong culture of reading among learners. Use of authentic texts from the Internet or electronic ER tools with built-in, automatically graded quizzes are examples of this type. 
In terms of integration in the curriculum, ER can also be classified as: 1) standalone course; 2) course component; 3) extra-curricular activity; or 4) homeroom activity (Day et al, 2011). As a stand-alone program, it may be offered as a separate course or subject in the curriculum with its corresponding learning outcomes, instructional activities, and assessment schemes. As a course component, it can be part of the learning/enrichment activities of the course with corresponding weightage in the course grading system. Students may read independently or in a group, in-class or at home, then participate in group discussion, report summary of the story, or write a reaction paper or alternative ending of the story. These activities carry corresponding marks. As an after-school or extra-curricular activity, the program is run by a school club and students voluntarily participate in the ER activities without any corresponding grade or academic merit. Students engage in activities as form of leisure or personal enrichment. Lastly, as a homeroom type, ER is designed as classroom activity with dedicated homeroom hour for students to select and read books. Students may or may not receive grades for participating in ER activities.

As an approach, ER is implemented with many different practices, activities, and materials depending on the context. Generally, teachers require students to read books or long texts in class or at home, and then check their understanding through short, automated quizzes, oral presentations, discussions, story map outlines, book reports, creative outputs, or performances. In some well-off schools, teachers use electronic/online ER platforms like M-Reader or XReading to make ER implementation more efficient. In some other schools, teachers depend on conventional activities and materials like physical graded readers from publishers or long texts accessible through the Internet.

In the study of Yamashita (2013), students were required to do 45-minute in-class silent reading for 15 weeks and produce a written report for each book in order to earn a grade. In a different study by Macalister (2008) at a university in New Zealand, ER was integrated in an EAP course through a daily 20-minute ER session followed by retelling activities for average-level students and a write-before-you-read activity followed by 20 -minute silent reading in class for advanced students.

Using a blended ER model, Suk (2017) implemented English ER for 15 weeks over the course of one semester where students completed 30-minute in-class ER activities using graded readers plus 70-minute out-of-class intensive reading using the textbook for each week. He used ER activities like scaffolded silent reading, writing a paper in 3 minutes, examining book blurbs, listening to a story and writing a response, and online quiz for graded readers using M-Reader. Students had to pass all M-Reader quizzes and read at least 200,000 words per semester in order to earn $25 \%$ of the overall course grade. Lin (2014) also implemented an online English ER program in Taiwan. His ER design included one class period for in-class reading every week coupled with unlimited out-of-class reading of long texts using mobile devices and electronic/online resources. 
In addition, Peel (2015) conducted an ER program for EFL students taking up intensive English program in the United States. Guided by a schedule, his ER program was structured for 8 weeks with 100 minutes per week. Initially, the students had to read teacher-selected texts, and then eventually students had to choose texts of their own liking. At the beginning, students started with easy, short texts, and then gradually moved to long, complex texts. The ultimate goal of the program was to lead the students to get to read at least one book per week. This was approached in a gradual manner, considering the students' pace, ability, motivation, and self-confidence. Structured in a scaffolded framework, in-class ER activities decreased while home-based ER activities increased as the course progressed. Students had to complete a reading log each week to foster accountability. ER activities included class/small-group discussions, dyads, 1-sentence summary, talk for a minute, and page gallery.

In implementing ER program regardless of context, Bell (1998) advised practitioners to involve students in managing resources, maintain regular dialogue with them regarding the books/texts they read, and conduct read-aloud sessions to help weaker students. He further recommended the establishment of a class library and use of audiobooks, multimedia and electronic resources to give students a wide array of options. Finally, he suggested that teachers should closely monitor student progress, give continuous feedbacks on students' written output, uphold a culture of accountability, and encourage students to read more and more.

While ER in many forms, structures and activities brings many benefits to L2 learners, its implementation is not without any problems or struggles. In most settings, making sufficient and varied reading materials easily accessible to all students and getting them to actually read are among the most commonly faced problems (Campbell \& Weatherford, 2013; Day \& Bamford, 1998; Hinkleman, 2013; Robb \& Kano, 2013). In addition, changing negative attitude toward extensive reading remains an uphill struggle among teachers. Moreover, creating a space for ER in a heavy-loaded curriculum and designing customized ER activities for varied learners also seem difficult for untrained teachers (Maley, 2009). Lastly, efficiently monitoring English reading progress, giving timely feedback to students (Cote \& Milliner, 2015), and balancing the pressure of national exams with ER activities seem taxing for already overburdened and exhausted teachers.

In the study of Huang (2015) in Taiwan, it was revealed that students did not engage in extensive reading in English because of many school pressures and because of the belief that it could not help them excel in their exams and academic performance. In Hong Kong, teachers were also reluctant to implement English ER due to heavy workload, fatigue, and lack of proper training (Green, 2005). In addition, students did not take it seriously because it was not part of a curriculum and assessment scheme where they can get some grades. Chien and Yu (2015) also revealed some reasons why teachers are reluctant in using graded readers for English ER programs. They believed that simplified texts (Graded Readers) are not authentic texts. Using simple, limited vocabulary and language features, these materials would 
not expand learners' vocabulary and would eventually slow down the rate of their natural language acquisition.

In a different study conducted by Domenica (2010), another struggle encountered by untrained teachers was their lack of skills in planning and designing extensive reading activities, selecting appropriate materials, crafting ER procedures and guidelines, assigning students to the right reading/book levels, guiding and motivating students to read, ensuring accountability among students, and inculcating the value of ER by serving as role model to students. Maley (2009) also identified reasons why not all teachers are doing ER. First, it requires a lot of time and effort. Second, materials are expensive, hence limited and inaccessible. Third, it is not part of the curriculum and assessment system. Fourth, teachers lack knowledge and skills in using ER. Fifth, teachers place more focus on achieving the desired learning outcomes and helping students score high in exams. Sixth, school stakeholders hold negative attitudes toward ER. Seventh, many students cannot and do not read. Lastly, young learners these days prefer online games and social media to reading long texts or books.

In Saudi Arabia, implementing and sustaining English ER is also extremely difficult. This is because of the absence of strong reading culture in the country, noninclusion of ER in the basic education national curriculum, teachers' lack of training in properly using ER in classrooms, and the unwillingness of teachers to go beyond the prescribed curriculum (Al-Nafisah, 2015). In the study by Meniado (2018), the common problems encountered in implementing ER include lack of sufficient reading books to choose from, lack of monitoring and support from teachers, lack of time to read, inability to comprehend, and lack of conducive places for silent reading. These findings highlight institutional (i.e., lack of resources and facilities), teacher-related (i.e., support), and student-related problems encountered in using ER as an approach in teaching reading.

The ER approach has been in place in the Arabian Gulf region for many years now. In fact, an organization called the Middle East and North Africa Extensive Reading Foundation (http://menaerf.org/) was established to promote the practice across the region. However, only few schools, colleges, and universities have adopted and sustained the approach. Based on literature reviews and the researcher's observations, some higher education institutions (HEIs) adopted the approach but eventually failed due to unsuitable practices and unsupportive policies, perspectives, and systems.

This study aimed to investigate English ER practices that effectively work in different higher education institutions (HEIs) in the Arabian Gulf region to build a repertoire of valuable and relevant practices that can be adapted by other HEIs to make ER programs in the region widespread and sustainable. Guided by this purpose, this study intended to answer the following research questions:

- What ER models or approaches are adopted by different HEIs across the Arabian Gulf region? 
- What ER practices and activities are implemented by HEIs across the region?

- What challenges or difficulties are encountered by HEIs in implementing an ER program?

The present study is the first attempt to map out ER approaches and activities in the Arabian Gulf region, particularly in the higher education context. While many studies have already conducted empirical investigations on the effectiveness of various ER practices across the globe, no single study has comprehensively documented the models, procedures and activities that are applicable and effective among EFL learners across the Arabian Gulf. The findings of this study can be useful for different teaching institutions in the region which are keen to integrating ER in their curriculums. Providing some models can guide them in designing and implementing ER activities that are appropriate in their own contexts. Further, documenting practices of other Arab colleges and universities, this study can inspire other institutions to follow, thereby making the practice of ER more widespread throughout the region. Moreover, this study can also help curriculum developers in integrating ER in pre-service and in-service teacher development programs. Lastly, it can expand existing ER literature and provide relevant information necessary in formulating needed policies towards more contextualized and sustainable ER across the region.

\section{Method}

Since the main purpose of this study was to holistically and insightfully examine the English extensive reading practices applied in various higher education institutions in the Arabian Gulf region through narratives and published documents, the qualitative research design was employed (Mertler, 2019). Data used in the study included articles published on the official websites of colleges and universities in the region, research studies documenting the implementation of English ER programs in various Arabian Gulf countries, and responses to the interview questions sent to heads and teachers in the intensive English programs (IEP) and English for academic purposes (EAP) programs of different colleges and universities. A total of seventeen government and private colleges and universities were involved in the study with seven from Saudi Arabia, three from Oman, two from United Arab Emirates, two from Qatar, two from Bahrain, and one from Kuwait. Out of hundreds of colleges and universities in the region, these institutions emerged as implementers of English extensive reading programs. They represent a small fraction of the total higher education institutions (HEIs) in the region, suggesting a very limited implementation of English ER across the Arabian Gulf.

Using online search tools and databases, relevant articles were looked for using such keywords as "extensive reading in the Arabian Gulf region," "extensive reading in Saudi Arabia," extensive reading in UAE," "extensive reading in Bahrain," "extensive reading in Qatar," "extensive reading in Oman," and "extensive reading in Kuwait". Search results yielded more than 20 relevant articles. However, filtering 
them through certain parameters such as empirical studies conducted in higher education context from 2010 to 2020, nine desired journal articles were selected. Each article described the ER model and activities implemented in a particular college or university. In addition to the articles, the researcher also contacted prominent HEIs in the Gulf region offering Foundation Year Programs, Intensive English Programs, and English for Academic Purposes (EAP) programs. HEIs were asked if they have been implementing or have previously implemented ER programs. Further, they were also asked how they implement ER, what model they use, and what activities they do. Of the twenty-three (23) contacted HEIs, nine responded. Considering the low turnout, other ways of increasing the response rate were considered. Individual websites of notable HEIs in the region were examined to find out if by any chance they were implementing (or had implemented) ER as independent or integrated activity in their curricula. Syllabi of English courses in the identified HEIs were scrutinized to look for indications of ER integration. Three institutions that published their ER programs on their institutional websites were identified. This made the total number of sources 20. However, it is important to note that some colleges and universities had their ER programs published on their websites, responded to the interview, and were also found in the journal articles at the same time. Repeated institutions were then counted as one, bringing the final total number of institutions down to seventeen (17).

Each journal article and online document (syllabus, course information, and news article) was content-analyzed focusing on the research questions under investigation. Based on the descriptions, guidelines, and procedures found in the articles, the institutional ER programs were categorized according to existing models and continuums proposed by Day (2015) and Day et al. (2011). The ER programs were classified according to approach and resources (e.g., Class Readers, Graded Readers, Reading Circles), structure (e.g., Supervised, Independent, Blended), and curriculum integration (e.g., stand-alone course, course component, extra-curricular activity, homeroom activity). After identifying the classifications of ER programs, the common ER activities implemented in all the institutions involved, ranging from pre-, during, and post-ER sessions were analyzed. Lastly, the best practices and weaknesses of the different institutional ER programs as well as the problems and difficulties encountered during the implementation were also looked into.

Aside from examining published articles and documents, interviews were also conducted to explore more HEIs implementing English ER and to gather more sufficient data on how ER programs are implemented in different parts of the region. The interview questions were based on the specific research questions of this study so that the responses could be easily matched with the data gathered from the articles and online documents. The interviews were conducted through email. First, the researcher emailed the department heads of English language programs of twentythree (23) prominent HEIs in the region, using the emails published in their institutional websites. Nine out of twenty-three HEIs responded. Some heads answered the questions directly by themselves, while others directed the researcher to 
the concerned faculty member who is (was) in-charge of the extensive reading program. Initially, HEIs were asked if they had been implementing (or previously implemented) ER. If the answer was "No", the HEI would be excluded from the study, and if the answer was "Yes", follow up questions were sent through email asking about the institutional ER approach adopted, the program structure, its integration in the English language curriculum, its duration, activities and resources used, assessment system, and the challenges encountered. Responses were consolidated with the data gathered from the published ER articles and institutional websites and were summarized in the tables in the next section.

\section{Results}

This section presents the summary of extensive reading (ER) models and approaches, guidelines and activities, and common problems encountered by higher education institutions (HEIs) across the Arabian Gulf region.

\subsection{ER models and approaches}

Table 1. Frequency distribution of HEIs implementing varied ER models and approaches in six Arabian Gulf countries

\begin{tabular}{|c|c|c|c|c|c|c|c|}
\hline $\begin{array}{l}\text { Types I } \\
\text { Classifications }\end{array}$ & $\begin{array}{l}\text { Saudi } \\
\text { Arabia }\end{array}$ & $\begin{array}{l}\text { United Arab } \\
\text { Emirates }\end{array}$ & Qatar & Bahrain & Oman & Kuwait & Total \\
\hline \multicolumn{8}{|l|}{ Approach } \\
\hline Class Reader & 1 & & & & & & 1 \\
\hline Graded Reader & 6 & 2 & 2 & 2 & 2 & 1 & 15 \\
\hline Reading Circle & & & & & 1 & & 1 \\
\hline \multicolumn{8}{|l|}{ Structure } \\
\hline \multicolumn{8}{|l|}{ Supervised ER } \\
\hline Pure ER & 1 & & 1 & & & & 2 \\
\hline Modified ER & 4 & 2 & 1 & 2 & 2 & & 11 \\
\hline ER Light & & & & & 1 & & 1 \\
\hline \multicolumn{8}{|l|}{ Fringe ER } \\
\hline Independent ER & 1 & & & & & & 1 \\
\hline Blended ER & 1 & & & & & 1 & 2 \\
\hline \multicolumn{8}{|l|}{$\begin{array}{l}\text { Curriculum } \\
\text { Integration }\end{array}$} \\
\hline Stand-alone course & & & 1 & & & & 1 \\
\hline Course component & 6 & 2 & 1 & 2 & 3 & 1 & 15 \\
\hline $\begin{array}{l}\text { Extra-curricular } \\
\text { activity }\end{array}$ & 1 & & & & & & 1 \\
\hline Homeroom activity & & & & & & & \\
\hline
\end{tabular}

Table 1 shows the frequency distribution of higher education institutions (HEIs) in the Arabian Gulf region in terms of ER approaches, structure, and curriculum integration. As reflected, fifteen out of seventeen HEIs adopted the graded readers approach, where simplified texts / books were used as main resource in integrating 
ER in the curriculum. Further, fourteen HEIs also adopted the supervised ER structure, where eleven of which used the modified ER. As discussed in the literature review, Modified ER is the type of instructed extensive reading program where most (not all) ER principles are followed. Lastly, fifteen HEIs integrated ER into their English language curriculum as a course component. This means that ER was part of the course learning design, delivery, and assessment.

\subsection{ER practices across the Gulf Region}

Table 2. Summary of identified ER practices in various Arabian Gulf countries

\begin{tabular}{|c|c|}
\hline Components & Descriptions \\
\hline Program duration & 1 semester up to 3 semesters \\
\hline Number of in-class sessions & 1 day up to 4 days a week \\
\hline Hours per in-class session & At least 20 to 50 minutes sustained silent reading per session. \\
\hline Desired out-of-class reading & At least 1 hour a day \\
\hline Number of graded readers required & $\begin{array}{l}\text { Some universities required at least } 4 \text { short stories per semester, while } \\
\text { others required at least } 10 \text { graded readers per semester }\end{array}$ \\
\hline Target number of words & $\begin{array}{l}10,000 \text { to } 100,000 \text { words per semester, depending on the students' } \\
\text { language proficiency / course level }\end{array}$ \\
\hline Resources / Platform & $\begin{array}{l}\text { Graded readers from Oxford University Press, Macmillan, Cambridge } \\
\text { University Press, and National Geographic; online graded readers and } \\
\text { quizzes available on XReading and M-Reader platforms; uploaded ER } \\
\text { quizzes in institutional learning management system (LMS) }\end{array}$ \\
\hline \multicolumn{2}{|l|}{ Activities } \\
\hline Pre-ER & $\begin{array}{l}\text { Institutional or classroom-based ER Program orientation, determining } \\
\text { reading levels and preferences of students through reading tests and } \\
\text { inventories, setting a minimum weekly reading word limit, warm-up } \\
\text { activities focusing on intensive reading skills (e.g., scanning, skimming, } \\
\text { previewing, studying grammatical structures, etc.) }\end{array}$ \\
\hline During ER & $\begin{array}{l}\text { Individual silent reading of a chosen graded reader or assigned class } \\
\text { reader, students reading aloud to class, students reading aloud one-on- } \\
\text { one with the teacher, and students independently reading in the library } \\
\text { during ER period, reading at home }\end{array}$ \\
\hline Post-ER & $\begin{array}{l}\text { Taking quizzes readily available on M-Reader and XReading platforms or } \\
\text { those that are manually uploaded by teachers to institutional LMS, group } \\
\text { or whole-class discussion, completing story map outline or book report, } \\
\text { oral presentation on the summary of the book/story with corresponding } \\
\text { creative visuals like PowerPoint slides, movies and posters, writing } \\
\text { reaction papers, completing a vocabulary notebook, and completing a } \\
\text { reading log }\end{array}$ \\
\hline Motivation strategies & $\begin{array}{l}\text { Gamifying ER (a leaderboard showing top readers of the week is } \\
\text { displayed on the ER platform), teacher coaching, awards ceremony for top } \\
\text { readers }\end{array}$ \\
\hline Assessment & $\begin{array}{l}\text { Quizzes, summary report (oral or written), story/book report, reaction } \\
\text { paper, presentation, creative performance }\end{array}$ \\
\hline Weightage & $\begin{array}{l}5 \% \text { to } 10 \% \text { of the final course grade; } 100 \% \text { for stand-alone ER course; Non- } \\
\text { graded for extra-curricular/after-school ER }\end{array}$ \\
\hline
\end{tabular}

Table 2 outlines the ER practices implemented by different higher education institutions in the Arabian Gulf region. As reflected, there is a wide range of requirements in terms of program duration, number of sessions, and target number of 
words. Some colleges and universities implemented ER for one semester while others did up to three semesters with at least one session up to four sessions a week. Those adopting Supervised/Instructed ER integrated the program as part of instruction giving a space for at least 20 to 50 minutes per session. The amount of target words per semester had a very wide range from at least 10,000 in some HEIs to at least 100,000 in others. Some schools also used the conventional way of using physical/printed graded readers available in physical libraries, while others used digital books uploaded in learning management systems such as XReading and MReader. The implementation procedures and activities also varied from one institution to another depending on the level of students and the course where the ER was integrated. As shown, some common activities included sustained silent reading in class and at home, taking quizzes, and doing some language enrichment activities such as report writing, oral presentation, and group discussion. Lastly, HEIs also varied in terms of ER weightage in the grading system. Those implementing ER as stand-alone courses took $100 \%$ of the course grade from ER activities, while those integrating it as component of language course gave $5 \%$ to $10 \%$ of the overall final course grade.

\subsection{Challenges in implementing ER programs}

Table 3. Challenges encountered by the Arabian Gulf HEIs in implementing ER program

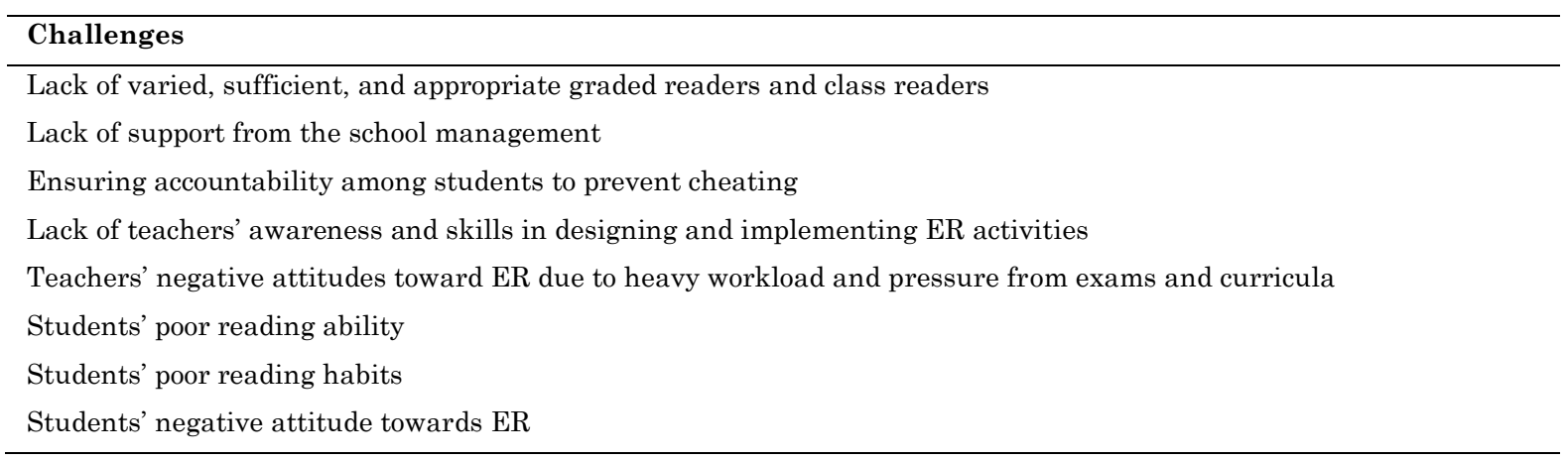

Table 3 presents the common problems or difficulties encountered by higher education institutions across the Arabian Gulf region in implementing their own models or versions of an extensive reading program. Deduced from the surveyed articles and email interviews, these identified challenges exist at institutional down to student levels. The issues range from limited resources to poor competencies and attitudes of school leaders, teachers and students. As reflected, some of the problems are short-term and structural, while others are systemic and cultural.

\section{Discussion}

The results indicate that the graded readers approach was adopted by most higher education institutions across the Arabian Gulf region. This is similar to the approach most commonly employed by HEIs in other regions like North America, East Asia, 
and Southeast Asia (Chang \& Renandya, 2017; Chien \& Yu, 2015; Milliner, 2016; Park, 2020; Peel, 2015). The use of this approach implies that HEIs comply with the basic ER principles requiring that reading materials should be appropriate to students' proficiency levels and that these materials should be varied with a wide range of interesting topics. It further implies that HEIs followed the ER principles requiring learners to have the freedom to choose texts/books they want to read and to have time to read individually and silently, as much as possible for pleasure, learning, and understanding. To sustain this practice, HEIs therefore need to implement innovative ways to monitor and encourage students to keep on reading, enrich class libraries with easier and more interesting materials, and maintain reliable accountability measures (Day et al, 2011). When HEIs uphold the ER principles, not only will the implementation of ER program in the region improve but also the culture of inclusivity, equity, empowerment, and learner autonomy developed.

In terms of structure, the most common ER model used in the region was the Supervised ER, specifically the Modified ER. This means that teachers designed, implemented, and supervised ER programs to serve the intended purpose. With the Modified ER, teachers made some changes in the established practices to meet the specific needs of the learners and learning contexts. As found in various literature, the Arab society does not have a strong culture of reading (Al-Damen, 2018; AlNafisah, 2015; Demirci, 2019). This means that Arab EFL learners do not read unless it is mandatory. Therefore, to make ER a pleasant experience among Arab learners, teachers need to modify the standards, guidelines, procedures, activities, materials, and assessment requirements. Contextualization is apparent in various HEIs as reflected in their varied standards and practices. While this is commendable, the ER principles (Bamford \& Day, 2002) should not be compromised to make ER implementation more sustainable and rewarding.

Findings also reveal that most HEIs across the region integrated ER programs in their curriculum as component of English language courses. Like other HEIs in various regions, it was either integrated as part of the Intensive English Program (IEP) or English for Academic Purposes (EAP) program. This kind of integration supports the optimal input hypothesis of Krashen (2019), which advances that learners become better L2 speakers or writers when they are exposed to comprehensible, compelling, meaningful, and abundant input, in this case written input, from various texts. English language teachers in the Arabian Gulf believe that Arab EFL learners can become proficient in English if they read a lot, and the best way to get them to read is to make ER part of the English curriculum where they get some external rewards such as grades.

As reflected in the findings, most HEIs share the same ER approach, structure, and curriculum integration scheme. However, it is also apparent that they have different standards, guidelines, and activities. This is because of their varying institutional policies, systems, and perspectives. Though they all serve Arab EFL learners, their circumstances in their respective countries vary. Some colleges and universities have better quality of intakes; hence, they establish higher standards in their ER 
programs. Others serve academically challenged students and thus have to do otherwise. Some also have sufficient funds to invest in graded readers and learning management systems such as XReading and M-Reader, while those economically challenged HEIs have to rely on limited resources in the school library and depend on some free resources from the Internet. Those with better students and teachers maintain more interesting and challenging ER activities, while those who have poor ones just rely heavily on assigning quizzes and plain one-paragraph summary reports. Finally, those who have more positive ER perspectives and established mechanisms in implementing ER tend to reward students more generously, and those that doubt their system of implementing the program tend to give ER a lower weightage. Clearly, several factors influence different ER practices in the region.

Results of this study also show that implementing ER is not an easy task. Like any other academic program, many challenges are involved. Based on the data gathered from the ER articles and interviews, the issue of maintaining varied, sufficient, and culturally appropriate graded readers and class readers is a great concern. Most HEIs do not have sufficient funds to sustain a rich collection of graded readers or easy access to ER technologies (XReading, M-reader, Newsela, etc.) for more effective and efficient implementation. There is also the problem of ensuring accountability among students, as there are many reported cases of cheating even with sophisticated tools and mechanisms. Due to large number of students in the Foundation / IEP programs in colleges and universities along with the heavy workloads of teachers, it is difficult to monitor cheating in (online) quizzes, control plagiarism in written outputs, and track swapping or sharing of ER projects among students from different sections or campuses. Furthermore, due to teachers' lack of training and negative attitudes towards ER, many are reluctant to implement the program properly. Lastly, due to the students' poor reading ability and reading habits and negative attitudes toward reading, only few students seriously engage in extensive reading. Most Arab EFL students are grade-oriented, so they mainly read for ER grade only, not for the holistic benefit from the program. These findings are consistent with the previous findings of Al-Damen (2018), Al-Nafisah (2015), Campbell \& Weatherford (2013), Meniado (2018), and Robb \& Kano (2013). These challenges impede the smooth integration of the ER principles, which can make the ER program unsuccessful. When HEIs do not have the sufficient resources, strong support from school leaders and teachers, and the full cooperation of the whole community, ER programs will eventually die a natural death. With the persistent challenges faced by HEIs, it is no wonder only few embrace and sustain ER for the ultimate benefits of Arab EFL learners and Arab society as a whole.

\section{Conclusions}

This study investigated the English ER models, approaches, and practices in the Arabian Gulf region and the challenges faced in the program implementation. Findings reveal that most English ER programs in the region adopted the Graded Readers approach with the Supervised-Modified ER model and Course Component 
integration scheme. Findings also indicate that ER programs varied in terms of duration, number of hours and sessions, target number of words, required number of books read, engagement and enrichment activities, and assessment system. Lastly, findings disclose that HEIs in the region experienced challenges in sustaining meaningful, varied, and sufficient resources, changing the negative attitudes of the stakeholders toward extensive reading, providing more sufficient space for ER in English language curriculum, and building a strong culture of reading in the community as a whole.

Based on the findings, it can be concluded that ER programs in the Arabian Gulf region resemble the most commonly used ER approach, structure, and curriculum integration scheme in many parts of the world. The Graded Readers approach dominates the ER landscape in the region, utilizing the Supervised-Modified ER model and Course Component integration scheme. ER standards and practices in the region also vary depending on the learner and learning contexts. Some institutions implement standards and practices that adhere to the ER principles, while others slightly deviate. These variations imply varied impacts on learners' proficiency and program effectiveness. Further, these differences also suggest a rich diversity of the ER practices in the region, hence the need for regional sharing, collaboration, and complementation to make ER a powerful tool for language and literacy development.

The diversity of ER culture in the region can be viewed as a strength rather than a weakness. It builds a repertoire of practices that expand ER literature, inform academics and scholars, and inspire classroom practitioners. The problems identified in the study not only pose threats to the sustainability of ER in the region, but also open new opportunities. Persistent and systemic, the presence of these problems suggest that classroom-based ER approaches employed through the years may not have been as effective as they seem, hence the need for a more strategic and holistic approach at a macro level. For ER to be helpful in improving the reading ability and overall language proficiency of Arab EFL learners, a stronger national or regional policy on extensive reading should be formulated to institutionalize reading as part of Arab culture across the region. Otherwise, extensive reading will just remain an advocacy in conferences and professional journals instead of it becoming a part of learners' lived experiences (Macalister, 2010). New policies could include permanent inclusion of ER in basic and higher education curriculum, provision of national budget for needed ER resources, and inclusion of ER in pre-service teacher education curriculum and in-service teacher training programs. In addition, active communities of practice on English extensive reading should be established and sustained for HEIs to share their best practices and to help one another in building and strengthening reading culture in the region.

While this study reported the common approaches, practices, and challenges faced in implementing ER in the Arabian Gulf region, its findings are limited as it draws on a relatively small sample of higher education institutions in the region. Though it used varied sources of data from large colleges and universities, the kind of data gathered does not represent the totality and diversity of all ER practices implemented 
in the region. Future studies along this line of inquiry may consider involving more colleges and universities using a more complex research design and data gathering tools. Future research into this issue may also include empirical investigation on the impacts of long-term ER programs on language and literacy development in the Arabian Gulf region.

\section{The Research and Publication Ethics Statement}

Data were collected after getting the consent of the participants. No ethical considerations were violated in this study.

\section{The Conflict of Interest Statement}

In line with the statement of Committee on Publication Ethics (COPE), I hereby declare that I had no conflicting interests regarding any parties of this study.

\section{References}

Abdellah, A. (2013). Training Saudi English majors in extensive reading to develop their standard-based reading skills. Journal of King Saud University -Languages and Translation, 25, 13-20. http://dx.doi.org/10.1016/j.jksult.2012.12.002

Al-Damen, T. M. (2018). The effectiveness of M-reader in promoting extensive reading among Arab EFL learners. Arab World English Journal (AWEJ). Proceedings of 1st MEC TESOL Conference 2018, 3-23. https://dx.doi.org/1024093/aw ej/MEC1.1

Al-Hammad, N. M. (2009). The role of extensive reading in L2 vocabulary acquisition: An empirical study on Saudi female students of the Department of English, King Saudi University (Unpublished master's thesis). King Saud University, Saudi Arabia.

Al-Homoud, F. A., \& Alsalloum, M. S. (2012). The effects of extensive reading on the breadth and depth of vocabulary knowledge and reading speed. Extensive Reading World Congress Proceedings, 1, 65-67. Retrieved from http://erfoundation.org/ proceedings/erwc1AlHomoud-Alsalloum.pdf

Al-Homoud, F. A., \& Schmitt, N. (2009). Extensive reading in a challenging environment: a comparison of extensive and intensive reading approaches in Saudi Arabia. Language Teaching Research, 13(4), 383-401. http://dx.doi.org/10.1177/ 1362168809341508

Al-Mahrooqi, R., \& Denman, C. (2016). Establishing a reading culture in Arabic and English in Oman. Arab World English Journal, 7(1), 5-17. http://dx.doi.org/10.24093/awej/vol7no1.1

Al-Mansour, N. S., \& Al-Shorman, R. A. (2014). The effect of an extensive reading program on the writing performance of Saudi EFL university students. International Journal of Linguistics, 6(2), 258-275. http://dx.doi.org/10.5296/ijl.v6i2.5551

Al-Nafisah, K. I. (2015). The effectiveness of an extensive reading program in developing Saudi EFL university students' reading comprehension. Arab World English Journal, 6(2), 98109. http://dx.doi.org/10.2139/ssrn.2834380

Al-Qahtani, A. A. (2016). Why do Saudi EFL readers exhibit poor reading abilities? English Language and Literature Studies, 6(1), 1-15. http://dx.doi.org/10.5539/ells. v6n1p1

Bamford, J., \& Day, R. (2002). Top 10 principles for teaching extensive reading. Reading in a Foreign Language, 14(2), 136-141.

Bamford, J., \& Day, R. (Eds.). (2004). Extensive reading activities for teaching language. Cambridge, England: Cambridge University Press. 
Bell, T. (1998). Extensive reading: why? and how?. The Internet TESL Journal, 4(12). http://iteslj.org/Articles/Bell-Reading.html

Campbell, J., \& Weatherford, Y. (2013). Using M-Reader to motivate students to read. In S. Miles \& M. Brierley (Eds.), Extensive Reading World Congress Proceedings (pp. 1-12). Seoul: Extensive Reading Foundation. Retrieved from http://erfoundation.org /ERWC2Proceedings.pdf

Chang, A.C.S., \& Renandya, W.A. (2017). Current practice of extensive reading in Asia. The Reading Matrix, 17(1), 40-58. http://www.readingmatrix.com/files/16-4vj138u3.pdf

Chien, C. C., \& Yu, K. (2015). Applying extensive reading to improve unmotivated learners' attitudes toward reading in English. International Journal of Learning, Teaching and Educational Research, 13(2), 1-25. https://www.ijlter.org/index.php/ ijlter/article/view/ 356/193

Cote, T., \& Milliner, B. (2015). Implementing and managing online extensive reading: student performance and perceptions. IALLT Journal of Language Learning Technologies, 45(1), 70-90. https://doi.org/10.17161/iallt.v45i1.8550

Day, R. (2015). Extending extensive reading. Reading in a Foreign Language, 27(2), 294-301. http://nflrc.hawaii.edu/rfl/October2015/discussions/day.pdf

Day, R., \& Bamford, J. (1998). Extensive reading in the second language classroom. New York: Cambridge University Press.

Day, R., et al. (2011). Bringing extensive reading into the classroom. Oxford: Oxford University Press.

Demirci, H.C. (2019). Extensive reading in the English as a second language classroom Motivating and engaging male Emirati students in a higher education context (uk.bl.ethos.778500) [Doctoral thesis, University of Liverpool]. https://dx.doi.org/10.17638/03045793

Domenica, P. (2010). Extensive reading in the classroom. MA TESOL Collection. Paper 486. https://core.ac.uk/download/pdf/232729306.pdf

Educational Testing Service [ETS]. (2015). Test and score data summary for TOEFL iBT tests: January 2014-December 2014 test data. New Jersey: Educational Testing Service. https://origin-www.ets.org/s/toefl/pdf/toefl_tsds_data_2014.pdf

Educational Testing Service [ETS]. (2016). Test and score data summary for TOEFL iBT tests: January 2015-December 2015 test data. New Jersey: Educational Testing Service. https://www.ets.org/s/toefl/pdf/toefl_tsda_data_2015.pdf

Educational Testing Service [ETS]. (2017). Test and score data summary for TOEFL iBT tests: January 2016-December 2016 test data. New Jersey: Educational Testing Service. https://origin-www.ets.org/s/toefl/pdf/toefl_tsds_data_2016.pdf

Educational Testing Service [ETS]. (2018). Test and score data summary for TOEFL iBT tests: January 2017-December 2017 test data. New Jersey: Educational Testing Service. https://origin-www.ets.org/s/toefl/pdf/toefl_tsds_data_2017.pdf

Educational Testing Service [ETS]. (2019). Test and score data summary for TOEFL iBT tests: January 2018-December 2018 test data. New Jersey: Educational Testing Service. https://www.toefl-ibt.jp/dcms_media/other/toefl_data.pdf

EF Education First. (2019). EF EPI: English proficiency index. Luzern: EF Education First Ltd. Retrieved from https://www.ef.com/assetscdn/WIBIwq6RdJvcD9bc8RMd/legacy/_/ /media/central efcom/epi/downloads/full-reports/v9/ef-epi-2019-english.pdf

Erguvan, D. (2016). Students' attitudes toward extensive and intensive reading and instructors' motivational strategies. Arab World English Journal, 7(2), 136-150. http://dx.doi.org/10.24093/awej/vol7no2.9 
Green, C. (2005). Integrating extensive reading in the task-based curriculum. ELT Journal, 59(4), 306-311. https://dx.doi.org/10.1093/elt/cci059

Hinkelman, D. (2013). Blending technologies in extensive reading: MoodleReader in a Japanese university EFL program.In S. Miles \& M. Brierley (Eds.), Extensive Reading World Congress Proceedings (pp. 91-100). Seoul: Extensive Reading Foundation. Retrieved from http://erfoundation.org/ERWC2-Proceedings.pdf

Huang, Y. C. (2015). Why don't they do it? A study on the implementation of extensive reading in Taiwan. Cogent 1099187. https://www.tandfonline.com/doi/full/10.1080/2331186X.2015.1099187

IELTS Partners. (2020). Test taker performance 2018. Retrieved from https://www.ielts.org/research/test-taker-performance

Krashen, S. [Stephen Krashen]. (2019, December 26). Optimal input [Video]. YouTube. https://www.youtube.com/watch?v=S_j4JELf8DA

Lin, C.C. (2014). Learning English reading in a mobile-assisted extensive reading program. $\begin{array}{llll}\text { Computers } \quad \text { Education, } & \text { 78(2014), }\end{array}$ http://dx.doi.org/10.1016/j.compedu.2014.05.004

Macalister, J. (2008). Integrating extensive reading into an English for academic purposes program. The Reading Matrix, 8(1), 23-33. http://www.readingmatrix.com/articles/macalister/article.pdf

Macalister, J. (2010). Investigating teacher attitudes to extensive reading practices in higher education: Why isn't everyone doing it? RELC Journal, 41(1), 59-75. http://dx.doi.org/10.1177/0033688210362609

Maley, A. (2009). Extensive reading: why it is good for our students... and for us. Retrieved from https://www.teachingenglish.org.uk/article/extensive-reading-why-it-goodour-students\%E2\%80\%A6-us

Meniado, J.C. (2018). Integrating extensive reading in a college preparatory year program: Perceptions, challenges, and possibilities. International Journal of English Language Education, 6(2), 50-68. https://doi.org/10.5296/ijele.v6i2.13624

Mertler, C.A. (2019). Introduction to educational research (2nd ed.). California: Sage Publications.

Milliner, B. (2017). One year of extensive reading on smartphones: A report. JALLTCALL Journal, 13(1), 49-58. Retrieved from https://files.eric.ed.gov/fulltext /EJ1141027.pdf

Nakanishi, T. (2015). A meta-analysis of extensive reading research. TESOL Quarterly 49(1), pp. 6-37. https://dx.foi.org/10.1002/tesq.157

Park, A.Y. (2020). A comparison of the impact of extensive and intensive reading approaches on the reading attitudes of secondary EFL learners. Studies in Second Language Learning and Teaching, 10(2), pp. 337-358. http://dx.doi.org/10.14746/ssllt.2020.10.2.6

Peel, M. (2015). Implementing an extensive reading program in an intensive university EAP curriculum (MA TESOL Collection 706) [Master's thesis, SIT Graduate Institute]. https://digitalcollections.sit.edu/ipp_collection/706

Robb, T. \& Kano, M. (2013). Effective extensive reading outside the classroom: A large-scale experiment. Reading in a Foreign Language, 25(2), 234-247. http://nflrc.hawaii.edu/rfl/October2013/articles/robb.pdf

Salameh, L. A. (2017). Investigating the effect of extensive reading on EFL learners' reading attitudes at Hail University in KSA. Journal of Education and Practice, 8(8), 7-15. http://www.iiste.org/Journals/index.php/JEP/article/view /36028/37022.

Schleicher, A. (2019). PISA 2018: Insights and interpretations. Paris, France: Organization for Economic Co-operation and Development [OECD]. 
Suk, N. (2017). The effects of extensive reading on reading comprehension, reading rate, and vocabulary acquisition. Reading Research Quarterly, 52(1), 73-89. https://doi.org/10.1002/rrq.152

Walker, C. (1997). A self-access extensive reading project using graded readers (with particular reference to students of English for academic purposes). Reading in a Foreign Language, 11(1), 121-149. http://nflrc.hawaii.edu/rfl/PastIssues/rfl111 walker.pdf

Yamashita, J. (2013). Effects of extensive reading on reading attitudes in a foreign language. $\begin{array}{llll}\text { Reading in } \quad \text { Foreign Language, } & \text { 25(2), } & \text { 248-263. }\end{array}$ https://files.eric.ed.gov/fulltext/EJ1015763.pdf

\section{Copyrights}

Copyright for this article is retained by the author(s), with first publication rights granted to the Journal. This is an open-access article distributed under the terms and conditions of the Creative Commons Attribution license (CC BY-NC-ND) (http://creativecommons.org/licenses/by-nc-nd/4.0/). 